\title{
Raiva em morcego não hematófago em área urbana do Município de Niterói - RJ*
}

\section{Rabies in a non-vampire bat in urban area of the Municipality of Niterói - RJ}

\author{
Flavio Fernando Batista Moutinho, ${ }^{* * * * *}$ Fabio Villas Boas Borges, ${ }^{* *}$ Paulo Mafra Fernandes, ${ }^{* *}$ Viviane Moura Azevedo Nunes, ${ }^{* *}$ \\ Maurício Rafael Domingues Rocha, ${ }^{* *}$ Cíntia Silva Santos, ${ }^{* *}$ Francisco de Faria Neto**
}

\begin{abstract}
Resumo
A raiva é uma antropozoonose que afeta mamíferos, com letalidade próxima de $100 \%$. O morcego é responsável pelo ciclo aéreo da enfermidade, o qual vem ganhando importância nos últimos anos. O presente manuscrito descreve um caso de raiva em morcego não hematófago ocorrido em 2013 na área urbana de Niterói, RJ. Através de seu sistema de vigilância passiva, o Centro de Controle de Zoonoses de Niterói (CCZ) recebeu uma notificação de presença de morcego com alterações clínicas em uma escola. $\mathrm{O}$ animal foi encaminhado para diagnóstico no laboratório de referência e o resultado das análises foi positivo para raiva tanto por Imunofluorescência Direta como por Inoculação Intracerebral em Camundongos Lactentes. De posse do resultado foi feita a notificação à Secretaria de Estado de Saúde e ao Sistema de Informação de Agravo de Notificação. Além disso, o setor de vigilância epidemiológica municipal procedeu à identificação dos indivíduos que tiveram contato com o animal, os quais foram encaminhados para avaliação médica e realização de soro-vacinação. O CCZ efetuou inspeção do local onde o morcego foi capturado e sugeriu modificações ambientais e realização de atividades educativas. Foi efetuado bloqueio vacinal em cães e gatos num raio de 500 metros do local de captura do animal. Conclui-se que há circulação ativa do vírus da raiva variante de morcegos no município. O ocorrido reforça a necessidade de manutenção da vigilância passiva, intensificação do monitoramento da circulação viral em morcegos e desenvolvimento de ações educativas junto à população em geral e aos profissionais de saúde.
\end{abstract}

Palavras-chave: vigilância, centro de controle de zoonoses, antropozoonose.

\begin{abstract}
Rabies is an anthropozoonosis that affect mammals, with lethality ratio close to $100 \%$. In Brazil bats are deemed as vector for the air cycle of the disease, whose the relevance has been increasing. This essay describes a case of rabies in a non-vampire bat taken place in 2013 in the urban area of Niterói, RJ. The Zoonosis Control Center of Niterói (CCZ) received, by its passive surveillance system, a notice about the presence of a bat with clinical alterations in a school. The animal was taken to the reference laboratory for diagnosis and the result was positive for rabies, by Direct Immunofluorescence and Intracerebral Inoculation in Suckling Mice. Upon such result, a notice was issued to the State Department of Health and to the Notification Aggravation Information System. Besides, the Municipal Epidemiological Surveillance Office proceeded to the identification of the individuals who have had contact with the animal and referred them for medical examination and serum vaccination. CCZ carried out an in-site inspection where the bat was captured and recommended environmental modifications as well as the development of educative activities. Vaccination was applied to cats and dogs within a ratio of 500 meters of the site. We concluded that there is an active circulation of the bat-variant rabies virus in the municipality. Such event reinforces the need of carrying out passive surveillance, intensifying the monitoring of viral circulation among bats and developing educative actions with the population in general, as well as with health care professionals.
\end{abstract}

Keywords: surveillance, zoonosis control center, anthropozoonosis.

\section{Introdução}

A raiva é uma das mais antigas enfermidades conhecidas pela humanidade, sendo uma antropozoonose que afeta todos os mamíferos e tem letalidade próxima de $100 \%$. A enfermidade apresenta quatro ciclos epidemiológicos: o urbano, envolvendo cães e gatos; o rural, envolvendo os animais de produção; o aéreo, envolvendo os morcegos, e o silvestre terrestre, envolvendo outros animais silvestres. O morcego é o responsável pelo ciclo aéreo da raiva, enfermidade que pode ser considerada importante problema sanitário (Brasil, 2009).

A raiva vem passando por uma mudança de seu perfil epidemiológico em que a transmissão por morcegos ganha importância em detrimento da transmissão por cães, logo, a vigilância e o monitoramento da raiva em morcegos deve ser intensificada (Wada et al., 2011). Já foram identificadas ao menos 41 espécies de morcegos positivos para raiva, sendo

*Recebido em 25 de novembro de 2014 e aceito em 26 de junho de 2015.

**Fundação Municipal de Saúde, Departamento de Vigilância Sanitária e Controle de Zoonoses, Centro de Controle de Zoonoses, Niterói, RJ, Brasil.

***Universidade Federal Fluminense, Faculdade de Veterinária, Departamento de Saúde Coletiva Veterinária e Saúde Pública, Laboratório de Vigilância em Saúde, Niterói, RJ, Brasil. Autor para correspondência: flaviomoutinho@id.uff.br 
43,9\% da família Phyllostomidae, à qual pertence o gênero Artibeus sp (Sodré et al., 2010), envolvido no presente caso.

\section{Relato do caso}

O Centro de Controle de Zoonoses (CCZ) do Município de Niterói mantém, dentre suas ações, a vigilância passiva da raiva em morcegos, conforme preconizado pelo Ministério da Saúde (Brasil, 2009). Foi por intermédio dessa vigilância passiva que, em 28 de novembro de 2013, o CCZ atendeu uma notificação da existência de um morcego com alterações clínicas e que deambulava no pátio de um complexo público de ensino.

$O$ referido morcego foi capturado no solo e com sinais de adoecimento por estudantes do complexo educativo, localizado no bairro Barreto, no intuito de protegerem e cuidarem do animal aparentemente doente. O quiróptero foi coletado pela equipe do CCZ e identificado como pertencente ao gênero Artibeus sp., não sendo possível a identificação da espécie em função da necessidade de rápido encaminhamento do animal para diagnóstico de raiva. Tal encaminhamento foi efetuado, em 29 de novembro de 2013, para a Unidade de Diagnóstico, Vigilância, Fiscalização Sanitária e Medicina Veterinária Jorge Vaitsman, da Prefeitura Municipal do Rio de Janeiro, RJ, que é referência para diagnóstico da raiva animal, onde já chegou morto. O resultado das análises realizadas foi positivo para raiva tanto pelo método da Imunofluorescência Direta como pelo método da Inoculação Intracerebral em Camundongos Lactentes.

De posse do resultado foi feita a notificação do caso à Secretaria de Estado de Saúde e no Sistema de Informação de Agravo de Notificação (SINAN), em 2 de dezembro de 2013. O setor de vigilância epidemiológica municipal procedeu à identificação dos indivíduos que tiveram contato com o animal, num total de quatro pessoas - três estudantes e um funcionário da escola, os quais foram encaminhados para avaliação médica e realização de soro-vacinação.

O CCZ efetuou, então, uma inspeção do local onde o morcego foi capturado, o qual é formado por diferentes unidades de ensino, com alguns prédios antigos propícios à colonização dos forros por quirópteros, além de uma importante junta de dilatação entre dois prédios. Havia, ainda, grande quantidade de árvores, inclusive frutíferas, propícias à colonização e à alimentação de morcegos frugívoros. O complexo de ensino fica localizado em área residencial próxima a uma área verde pública, que é tradicionalmente frequentada por idosos e crianças.

Nesse contexto, procedeu-se, ainda, a um bloqueio vacinal contra raiva de caninos e felinos em um raio de 500 metros ao redor do local da captura do animal, conforme preconizado pelo Instituto Pasteur (Kotait et al., 2003), tendo sido vacinados 78 cães e 18 gatos. Além disso, sugeriu-se à administração do complexo de ensino a poda das árvores do pátio e ao CCZ a realização de ações educativas para a comunidade e junto aos médicos-veterinários estabelecidos na região para aumentarem a vigilância frente à raiva.

\section{Discussões}

Entre 2002 e 2009, a transmissão da raiva por morcegos foi responsável por $45 \%$ dos casos humanos no Brasil, contra $47 \%$ da transmissão por cães. No mesmo período, $80 \%$ dos casos de raiva em morcegos ocorreu em espécies não hematófagas (Wada et al., 2011).

É comum que os morcegos com raiva sejam encontrados já doentes e com paralisia (Cunha et al., 2006), como aconteceu no presente caso, em que os estudantes, ao tentarem proteger e cuidar do animal, procuraram apoio de um funcionário da escola e todos manusearam o animal enfermo. Somente num momento posterior o CCZ foi procurado.

O bairro Barreto, localizado na zona norte de Niterói, é estritamente urbano e pesquisas vêm mostrando que a maior parte dos morcegos não hematófagos onde são isolados vírus rábicos provêm das zonas urbanas (Cunha et al., 2006). Espécies do gênero Artibeus, que são morcegos frugívoros, são comuns nos parques urbanos, onde encontram abrigos nos topos fechados das árvores (Muller \& Reis, 1992), inclusive nas mangueiras, como as que foram identificadas no complexo educativo em tela. Estudo envolvendo 7.393 morcegos oriundos de municípios das regiões norte e noroeste de São Paulo, entre 1997 e 2002 demonstrou que 33,7\% dos morcegos positivos para raiva eram da espécie $A$. lituratus, que foi a proporção mais elevada entre as espécies (Cunha et al., 2006).

Entre 2006 e 2010, houve 164 reclamações da comunidade envolvendo morcegos à Seção de Controle de População Animal do CCZ de Niterói, o que equivaleu a $10,7 \%$ do total de reclamações (Moutinho et al., 2013). Pesquisa realizada por Moutinho (2014) identificou que em 50\% dos municípios avaliados na Região Metropolitana II da qual faz parte Niterói houve registro de espoliação de animais domésticos por morcegos hematófagos no período 2008 a 2010. Importante salientar que, recentemente, foi identificado um paciente humano apresentando lesão ocasionada por morcego hematófago no bairro Sapê, em Niterói (Bernardes et al., 2014), e que a variante antigênica e genética do vírus rábico mais comumente encontrada em morcegos não hematófagos é a mesma mantida pelos morcegos hematófagos Desmodus rotundus (Albas et al., 2011).

A presença dos morcegos em áreas urbanas está relacionada com a destruição ambiental, ao crescimento urbano desordenado e a projetos arquitetônicos que propiciam a colonização por esses animais (Kotait et al., 2003). Apesar de se tratar de um problema complexo, é possível reduzir o risco potencial de infecção da população por intermédio das ações educativas no intuito de que as pessoas não manejem morcegos encontrados doentes ou feridos (Cunha et al., 2006) e notifiquem às autoridades a presença desses animais enfermos. No presente caso, os indivíduos manusearam o morcego doente, inclusive crianças, e somente num segundo momento acionaram o CCZ, ainda assim objetivando conseguir um tratamento para o quiróptero enfermo.

O morcego em questão foi encontrado próximo ao Horto Municipal Palmir Silva, uma área rica em árvores e que é frequentada de maneira contumaz por idosos e crianças em atividades de lazer (Figura 1).

A possível presença de animais domésticos abandonados em parques urbanos como este e nas vias públicas pode representar risco iminente de ocorrência de raiva nesses animais já que 


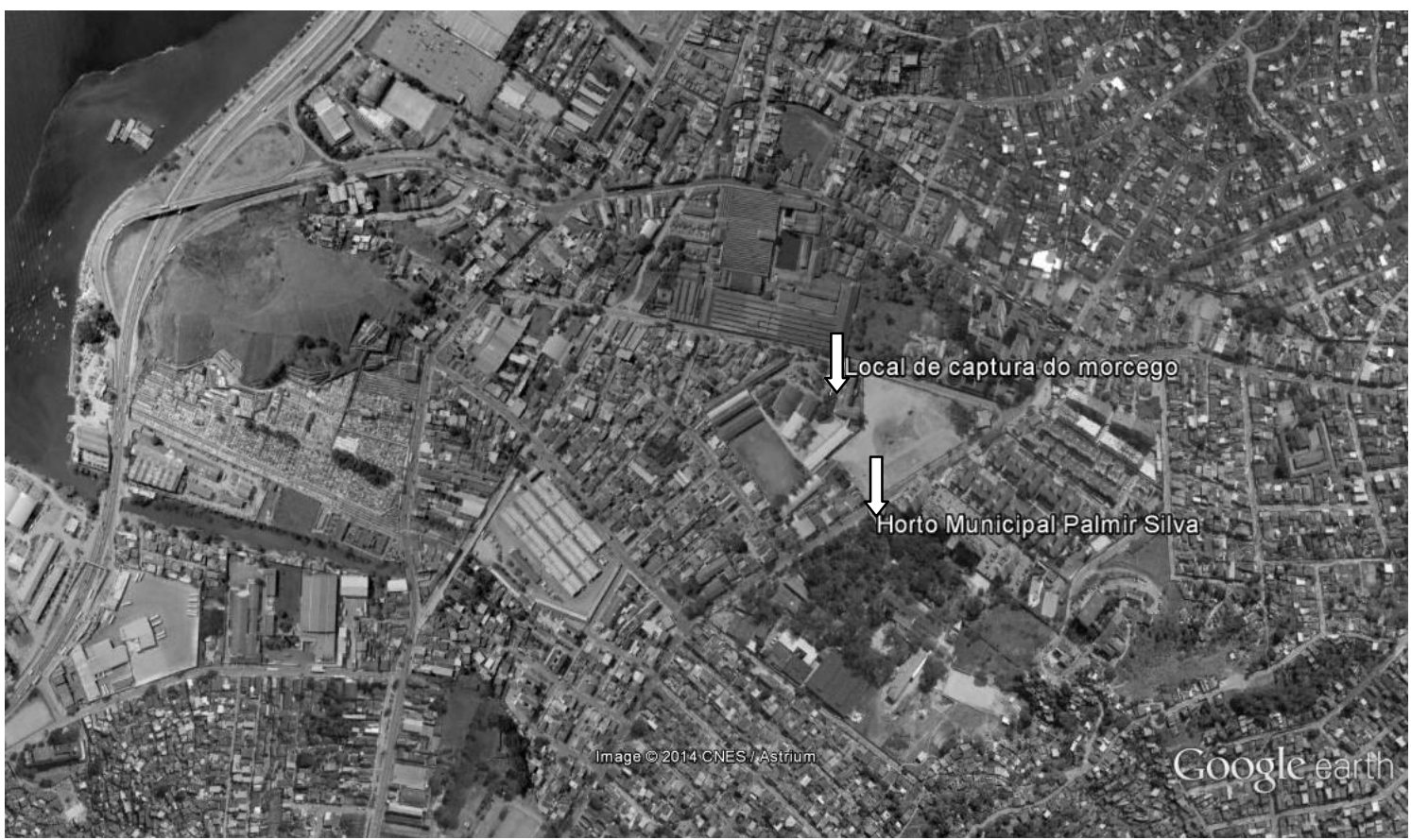

Figura 1: Local de captura do morcego e localização do Horto Municipal Palmir Silva, no bairro Barreto, área urbana de Niterói, RJ (Fonte: Google Earth).

eles podem entrar em contato com morcegos doentes (Silva et al., 2007). Há ainda o agravante do percentual de cobertura da vacinação contra raiva de cães e gatos ter alcançado somente $48,1 \%$ da meta em 2012 e $45,3 \%$ em 2013, o que pode ser creditado aos problemas de efeitos adversos da vacina que ocorreram na campanha de vacinação de 2010, levando à desmobilização da população e à desconfiança em relação ao imunobiológico utilizado. Tal situação aumenta o risco de ocorrência de raiva em animais domésticos no município.

A transmissão aérea foi responsável, nos últimos anos, pelo ressurgimento da raiva em animais domésticos em cidades como Curitiba, PR, onde a enfermidade não ocorria nesses animais havia 29 anos (Morikawa et al., 2012). Em pesquisa realizada por Moutinho (2014) foi detectado que 36 dos 47 municípios avaliados no estado do Rio de Janeiro não encaminharam

\section{Referências}

ALBAS, A.; CAMPOS, A. C. A.; ARAÚJO, D. B.; RODRIGUES, C. S.; SODRÉ, M. M., DURIGON, E. L.; FAVORETTO, S. $\mathrm{R}$. Molecular characterization of rabies virus isolated from nonhaematophagous bats in Brazil. Rev Soc Bras Med Trop , v. 44, n. 6, p. 678-683, 2011.

BERNARDES, F. F.; MARTINS, G.; LUCHI, G. S.; KAC, B. K.; NERY, J. A. C.; AZULAY-ABULAFIA, L. et al. Multiple lesions by vampire bat bites in a patient in Niterói, Brazil - Case report. An Bras Dermatol , v. 89, n. 2, p. 340-343, 2014.

BRASIL. Guia de vigilância epidemiológica. 7. ed. Brasília: Ministério da Saúde, 2009. 816 p.

CUNHA, E. M. S.; SILVA, L. H. Q.; SOUZA, M. C. C.; LARA, H.; NASSAR, A. F. C.; ALBAS, A.; SODRÉ, M. M.; PEDRO, W. A. Bat rabies in the northnorthwestern regions of the state of São Paulo, Brazil: 1997-2002. Rev Sau Pub, v. 40, n. 6, p.1082-1086, 2006. nenhuma amostra de material biológico de morcego para diagnóstico de raiva no período 2008-2010, o que equivale a $77 \%$ dos municípios pesquisados.

\section{Conclusões}

Conclui-se que há circulação ativa do vírus da raiva variante de morcegos no município de Niterói. Em face do exposto, torna-se imprescindível a manutenção da vigilância passiva, a intensificação do monitoramento da circulação viral da raiva em morcegos, hematófagos ou não, e o desenvolvimento de um projeto educativo visando à conscientização da população em geral e à sensibilização dos profissionais de saúde atuantes no município em relação à raiva, especialmente no tocante ao ciclo aéreo.

KOTAIT, I.; HARMANI, N. M. S.; CARRIERI, M. L.; SODRÉ, M. M.; PANACHÃO, M. R. I.; TAKAOKA, N. Y. Proposta de ações a serem desencadeadas para cobertura de foco de raiva em quirópteros em centros urbanos. In: Kotait et al. Manejo de quirópteros em áreas urbanas. São Paulo: Instituto Pasteur, 2003. $44 \mathrm{p}$.

MULLER, M. F.; REIS, N. R. Partição de recursos alimentares entre quatro espécies de morcegos frugívoros (Chiroptera, Phyllostomidae). Rev Bras Zool., v. 9, n. 3-4, p. 345-355, 1992.

SODRÉ, M. M.; GAMA, A. R.; ALMEIDA, M. F. Updated list of bat species positive for rabies in Brazil. Rev. Inst. Med. Trop. Sao Paulo. v. 52, n. 2, p. 75-81, 2010.

MORIKAWA, V. M.; RIBEIRO, J.; BIONDO, A. W.; FELLINI, A.; BIER, D.; MOLENTO, M. B. Cat infected by a variant of bat rabies virus in a 29-year disease-free urban area of southern Brazil. Rev Soc Bra Med Trop , v. 45, n. 2, p. 255-256, 2012. 
MOUTINHO, F. F. B.; ROCHA, M. R. D.; BORGES, F. V. B.;

PEREIRA, A. G.; SERRA, C. M. B. Reclamações da comunidade à Seção de Controle de População Animal do Centro de Controle de Zoonoses de Niterói, RJ, Brasil, no período 2006-2010. $R$ Bras Ci Vet, v. 20, n. 1, p. 26-31, 2013.

MOUTINHO, F. F. B. Percepção da sociedade sobre o controle populacional de cães não domiciliados e avaliação de fatores de risco para raiva no Estado do Rio de Janeiro (Tese de doutorado). Niterói: Faculdade de Veterinária / UFF: 2014. 111 f.
SILVA, M. V.; XAVIER, S. M.; MOREIRA, W. C.; SANTOS, B. C. P.; ESBÉRARD, C. E. L. Vírus rábico em morcego Nyctinomops laticaudatus na Cidade do Rio de Janeiro, RJ: isolamento, titulação e epidemiologia. Rev Soc Bra Med Trop, v. 40, n. 4, p. 479-481, 2007.

WADA, M. Y.; ROCHA, S. M.; MAIA-ELKHOURY, A. N. S. Situação da Raiva no Brasil, 2000 a 2009. Epidemiol. Serv. Saúde, v. 20, n. 4, p. 509-518, 2011. 